\title{
A Note on Distribution of Breeding Sources of Aedes aegypti (Linnaeus) in the City of Kolkata, India, Following an Outbreak of Dengue during 2012
}

\author{
Debashis Biswas*, Baishakhi Biswas, Bithika Mandal, Atanu Banerjee \\ Vector Control Department, Kolkata Municipal Corporation, Kolkata, India \\ Email: ${ }^{*}$ debashis.megh@gmail.com
}

Received 7 February 2014; revised 27 February 2014; accepted 11 March 2014

Copyright (C) 2014 by authors and Scientific Research Publishing Inc.

This work is licensed under the Creative Commons Attribution International License (CC BY). http://creativecommons.org/licenses/by/4.0/

\section{Open Access}

\section{Abstract}

An Aedes aegypti (larval) survey was conducted by the vector control department of Kolkata Municipal Corporation (KMC), following an outbreak of dengue in Kolkata City in July 2012. Results obtained are startling. Small discarded items were the major breeding sources of Ae. aegypti (prime vector of dengue). Outdoor containers such as battery shells at market places, old tyres at garages and tyre-retreading centres and wells at construction sites represented the first, second and third categories of preferred breeding sites of this vector mosquito. In the past, Ae. aegypti in Kolkata City was quite photophobic with regard to its breeding habit; it used to breed more indoors-mostly in small uncovered masonry tanks used for water storage indoors. But the very mosquito now breeds more outdoors; it has become photophilic. Ecological compulsion created by the people of Kolkata through periodic emptying and cleaning of their masonry tanks and other indoor water storage containers following the KMC's intensive mass awareness campaigns over the past several years, seemed to have compelled Ae. aegypti to shift its breeding sites from indoors to outdoors for its better survival in the city's environment. The need for active involvement of some other departments of KMC-besides the health department-such as the departments of solid waste management, building, water supply and drainage, too, was clearly pointed out by the study. Accordingly, multipronged strategies-including prompt destruction of the breeding sources of Ae. aegypti right from the month of January by involving all the concerned departments-were planned and religiously implemented by KMC during 2013. The concerted efforts yielded commendable results: the number of dengue cases downslided from a staggering 1852 (with 2 deaths) in 2012 to a comfortable 238 (with no death) in 2013.

*orresponding author.

How to cite this paper: Biswas, D., et al. (2014). A Note on Distribution of Breeding Sources of Aedes aegypti (Linnaeus) in the City of Kolkata, India, Following an Outbreak of Dengue during 2012. Current Urban Studies, 2, 57-61.

http://dx.doi.org/10.4236/cus.2014.21006 


\title{
Keywords
}

\author{
Kolkata City; Dengue; Aedes aegypti; Breeding Sources; Photophobic; Photophilic; Ecological \\ Compulsion
}

\section{Introduction}

The city of Kolkata has long experience of recurrent outbreaks of dengue and Aedes aegypti (Linnaeus) is the primary vector of the disease (Mukherjee, Chakraborty, Dey, Dey \& Chakraborty, 1987; Biswas, Biswas, Mandal, Banerjee, Mukherjee \& Nandi, 2011). As in many previous years, in 2012 too, the city witnessed an outbreak of this mosquito-borne disease. Reports of sporadic cases of dengue had been pouring in from some areas of the city since January 2012. But transmission of the disease in a massive way began in July and the episode continued till November. For prevention and control of the disease, the vector control department of Kolkata Municipal Corporation (KMC) mounted a city-wide drive for destruction of breeding sites of Ae. aegypti. While overseeing such Aedes control programme, entomologists (4 in all) and some other technical personnel of KMC came across a greater prevalence of the breeding sites of Ae. aegypti outdoors-a stunning change which was just the reverse of the findings of earlier studies. For planning future strategies against dengue, collecting detailed information about the breeding sources of Ae. aegypti was felt necessary and hence an Ae. aegypti (larval) survey was undertaken by the vector control department of KMC during July to December 2012 under the technical guidance of entomologists. Outcomes of the study are reported in this short communication.

\section{Materials and Methods}

\subsection{Profile of the KMC Area}

Inhabited by over 4.5 million people, the area of KMC sprawls over 206.2 square kilometres and is divided into 15 boroughs consisting of a total of 144 wards. There are 1500 registered slum clusters, where nearly $39.4 \%$ of the city's population live. People's water storage practice in some areas of the city is rampant. To meet people's growing need for accommodation, construction of buildings/sky-scrapers is going almost everywhere in the city at a blistering pace. The city is fast expanding vertically. The city's daily floating population is around 6 million.

\subsection{City's Climate}

Three meteorologically discernible seasons characterise the climate of Kolkata City—rainy season (July to October), dry winter (November to February) and moderately hot and humid summer (March to June). The city's average minimum temperature and maximum temperature are 12 degrees Celsius and 38 degrees Celsius respectively. The average daily humidity here varies from $57.2 \%$ to $86.0 \%$. The city's annual rainfall is $1400-1600$ millimetres.

\subsection{Methodologies}

Four Rapid Action Teams-comprising 10 to 12 trained field workers each-were detailed for the study. These teams were formed in December 2010 for vector surveillance. One Rapid Action Team inspected 2 new wards in every month and each ward was visited twice by the team. In all 48 wards were surveyed by four Rapid Action Teams during July to December 2012. The search for Ae. aegypti larvae in each ward was made mainly in the areas that had reported cases of dengue. Fifty to 75 houses per ward per visit were inspected at random. Human-dwellings apart, under-construction buildings, schools, colleges, universities, medical colleges, hospitals, office buildings, workshops, garages (both public and private), tyre-retreading centres, market places too were inspected by the Rapid Action Teams for Ae. aegypti breeding sources.

Identification of Ae. aegypti larvae was done quite deliberately. Since the survey was a part of the anti-dengue drive of KMC, mosquito larvae were destroyed soon after their detection using need-based measures. Number and types of water containers checked and those found positive for Ae. aegypti larvae both indoors and outdoors were recorded in every month. 


\section{Results}

In all 44332 open water containers of 17 types were searched, of which 6495 (14.6\%) were positive for Ae. aegypti larvae. Small discarded items_comprising 58.3\% (3771) of breeding containers_-were the major breeding sources of Ae. aegypti (Table 1). The percentage distribution of some other important breeding sources of this vector mosquito in descending order was: unused tyres (9.8), battery shells (9.5), drums made of polyvinyl chloride (8.3) and scraps (7.4). Masonry tanks, open overhead water tanks, buckets, water storage tanks at construction sites, flower pots, earthen pitchers, sites with seepage water, tin cans, open drains, lift-wells, coconut shells and wells were of minor importance and they together comprised 6.7\% (451) of the breeding containers.

Over $15 \%$ of the outdoor containers were positive for Ae. aegypti larvae, while among the indoors, only $2.6 \%$ containers were positive, thereby implying that the outdoor containers were more conducive to the breeding of Ae. aegypti than the indoor ones. When proportions of different categories of breeding containers of this vector species were compared, battery shells_-in which florists had stored water to keep sticks of jasmine flower fresh

Table 1. Distribution of Aedes aegypti breeding sources in some dengue-affected wards of Kolkata Municipal Corporation during July to December 2012.

\begin{tabular}{|c|c|c|c|c|c|c|c|}
\hline \multirow[t]{2}{*}{$\begin{array}{l}\text { Places inspected } \\
\text { (with number) }\end{array}$} & \multirow[t]{2}{*}{$\begin{array}{l}\text { Type of water containers } \\
\text { checked for mosquito larvae }\end{array}$} & \multicolumn{2}{|c|}{$\begin{array}{l}\text { Number of containers } \\
\text { checked }\end{array}$} & \multicolumn{2}{|c|}{$\begin{array}{l}\text { Number of containers } \\
\text { found positive } \\
\text { for Aedes aegypti larvae }\end{array}$} & \multicolumn{2}{|c|}{$\begin{array}{c}\text { Relative distribution of } \\
\text { containers with Aedes } \\
\text { aegypti larvae (\%) }\end{array}$} \\
\hline & & Indoor & Outdoor & Indoor & Outdoor & Indoor & Outdoor \\
\hline \multirow{5}{*}{ Houses (5800) } & Masonry tanks & 1256 & 790 & 10 & 29 & 0.79 & 3.67 \\
\hline & Open overhead tanks & 0 & 552 & 0 & 78 & 0 & 14.13 \\
\hline & Flower pots & 0 & 1184 & 0 & 38 & 0 & 3.20 \\
\hline & $\begin{array}{l}\text { Sites with seepage } \\
\text { water on rooftops }\end{array}$ & 0 & 369 & 0 & 24 & 0 & 6.50 \\
\hline & Open drains & 0 & 158 & 0 & 6 & 0 & 3.79 \\
\hline \multirow{5}{*}{$\begin{array}{l}\text { Schools (55), colleges (7), } \\
\text { universities (3), medical } \\
\text { colleges (5) and } \\
\text { hospitals (7) }\end{array}$} & $\begin{array}{c}\text { Discarded items } \\
\text { (cups, pots, cans, bottles, etc.) }\end{array}$ & 0 & 2316 & 0 & 238 & 0 & 10.27 \\
\hline & Open overhead tanks & 0 & 98 & 0 & 6 & 0 & 6.12 \\
\hline & Masonry tanks & 32 & 69 & 2 & 9 & 6.25 & 13.04 \\
\hline & Open drains & 0 & 49 & 0 & 5 & 0 & 10.20 \\
\hline & Drums (PVC) & 107 & 628 & 9 & 140 & 8.41 & 22.29 \\
\hline \multirow{5}{*}{$\begin{array}{l}\text { Under-construction } \\
\text { buildings (125) }\end{array}$} & Water storage tanks & 52 & 309 & 5 & 51 & 9.61 & 16.50 \\
\hline & Lift-wells & 4 & 56 & 0 & 9 & 0 & 16.07 \\
\hline & Wells & 0 & 21 & 0 & 5 & 0 & 23.80 \\
\hline & Drums (PVC) & 271 & 1758 & 11 & 378 & 4.05 & 21.50 \\
\hline & Buckets & 88 & 1560 & 2 & 79 & 2.27 & 5.06 \\
\hline \multirow{5}{*}{ Slum clusters (52) } & Earthen pitchers & 122 & 1066 & 0 & 36 & 0 & 3.37 \\
\hline & Masonry tanks & 92 & 245 & 4 & 28 & 4.34 & 11.42 \\
\hline & Tin cans & 12 & 158 & 0 & 16 & 0 & 10.12 \\
\hline & Battery shells & 29 & 216 & 12 & 191 & 41.37 & 88.42 \\
\hline & Scraps & 0 & 4374 & 0 & 479 & 0 & 10.95 \\
\hline \multirow[t]{2}{*}{ Workshops and garages (8) } & Old tyres & 0 & 433 & 0 & 259 & 0 & 59.81 \\
\hline & Battery shells & 0 & 98 & 0 & 82 & 0 & 83.67 \\
\hline Tyre-retreading centres (4) & Old tyres & 0 & 537 & 0 & 377 & 0 & 70.20 \\
\hline \multirow{3}{*}{ Market places (28) } & $\begin{array}{c}\text { Discarded items } \\
\text { (cups, pots, cans, bottles, etc.) }\end{array}$ & 0 & 850 & 0 & 81 & 0 & 9.52 \\
\hline & Battery shells & 0 & 367 & 0 & 335 & 0 & 91.28 \\
\hline & Coconut shells & 0 & 164 & 0 & 9 & 0 & 5.48 \\
\hline $\begin{array}{l}\text { Vacant plots (21) } \\
\text { in localities }\end{array}$ & $\begin{array}{c}\text { Discarded items } \\
\text { (cups, pots, cans, bottles, etc.) }\end{array}$ & 0 & 23,842 & 0 & 3452 & 0 & 14.47 \\
\hline Total & 17 types & 2065 & 42,267 & 55 & 6440 & 2.66 & 15.23 \\
\hline
\end{tabular}


and alive-represented the most preferred breeding sites of Ae. aegypti (87.3\%; 620/710). Unused tyres (65.5\%; 636/970), which had been lying stacked in the open space at garages, workshops and tyre-retreading centres, were the second preferred larval habitats of Ae. aegypti. The wells dug at the sites of under-construction buildings were the third preferred breeding sources of this mosquito $(23.8 \%$; $5 / 21)$. Water storage drums (made of polyvinyl chloride) at slum clusters and construction sites $(19.4 \%$; 538/2764), water storage tanks at construction sites (15.5\%; 56/361), lift-wells at construction sites (15\%; 9/60), discarded items stacked in the open space (13.9\%; 3771/27008) and open overhead tanks (12.9\%; 84/650) ranked fourth, fifth, sixth, seventh and eighth in the list of preferred Ae. aegypti breeding sites respectively.

\section{Discussion}

In the past, Ae. aegypti in the city of Kolkata used to breed more indoors, mostly in small uncovered masonry tanks (Paiva, 1912; Wattal, 1964; Gilotra, Rozeboom \& Bhattacharya, 1967; Biswas, 2007). In a study done here during 1990-1991 following an outbreak of dengue haemorrhagic fever, over 64\% of the breeding containers of Ae. aegypti were masonry tanks (395/615) used for water-storage indoors, and these tanks represented the insect's preferred breeding sites too (16.9\%; 395/2331) (Biswas, Dey, Dutta \& Hati, 1993). In other words, Ae. aegypti in the city was photophobic in bygone days with regard to its breeding habit. The greater prevalence of Ae. aegypti breeding containers indoors was presumably due to the temperature of water which was more congenial indoors than outdoors to the spawning of this mosquito (Cheong, 1967). The present survey, however, unfolded a completely different story: the breeding containers of Ae. aegypti were found more outdoors than indoors, thereby pointing to a change in the breeding habits of the mosquito- a change from photophobia to photophily. Though the water temperature in outdoor containers was much higher than in indoor containers, Ae. aegypti chose outdoor containers as its preferred spawning sites. Mass awareness campaigns by the health department of KMC over the past several years for proper cleaning of masonry tanks, drums and other such water storage containers at weekly intervals seemed to have created an ecological compulsion for Ae. aegypti to shift its breeding sites from indoors to outdoors for better survival in the city's environment.

Small discarded items (such as cups, pots, cans, bottles, etc.), unused tyres, battery shells and scraps seemed deadlier than other categories of containers. Presence of Ae. aegypti larvae in open drains and lift-wells was indeed quite annoying; it gave us a clear indication that Ae. aegypti could breed in filthy water too in case the situation so demands.

Based on findings of the study, the authorities of KMC planned various strategies during 2013 to prevent recurrence of dengue in the city. Free facilities for detection of dengue were provided through 5 KMC-run dengue detection centres. Disease surveillance mechanism for collecting dengue-reports from different non-KMC sources such as hospitals, nursing homes and private pathological laboratories was strengthened.

To prevent vector procreation in under-construction buildings and other construction sites around the city, an alert to the concerned promoters/developers was issued by the health department of KMC. Timely disposal of garbage (small plastic cups, bottles, tin cans, earthen teapots, domestic wastes, etc.) from residential areas in different vulnerable wards was done by the department of solid waste management. Cleaning of clogged open surface drains was done by the drainage department. Drive for integrated vector management was intensified in each and every ward of KMC right from the beginning of the year (January). In March, the number of Rapid Action Teams was enhanced from 4 to 21 to strengthen vector surveillance in different wards of KMC. Test reports concerning dengue were sent to the concerned patients and the officials of the department through SMS whenever the test results were available. Fever surveillance by detailing 850 honorary health workers was undertaken from February following the instructions of the Hon'ble Chief Minister of the state of West Bengal, Smt. Mamata Banerjee. To supplement these honorary health workers, 100 days field workers @12 workers per ward of KMC were deployed in March under West Bengal Urban Wage Employment Scheme.

Awareness-raising campaigns through various means (distribution of 3 lakh booklets, distribution of 8 lakh leaflets, putting up of 25 thousand banners and 750 hoardings, showing of a documentary film through LED digital screen for 10 hours a day for 60 consecutive days, awareness meetings in different wards (@ 4-5 meetings per ward) involving ward councillors, campaign through FM channels, campaign through electricity consumption bills issued by the Calcutta Electric Supply Corporation Limited, etc.) too were stepped up across the city. Hon'ble Member of the Mayor-in-Council (Health \& Engineering) of KMC, Shri Atin Ghosh, himself monitored the anti-dengue activities on a regular basis. 
The concerted efforts yielded commendable results. The number of dengue cases in the city came down phenomenally: from a dispiriting 1852 (with 2 deaths) in 2012 to a comfortable 238 (with no death) in 2013. An estimated \$US 15,000 was spent for completion of the study.

In its publication "Global Strategy for Dengue Prevention and Control, 2012-2020", the goals set out by the World Health Organization are to reduce dengue mortality by at least $50 \%$ and morbidity by at least $25 \%$ by 2020 (using 2010 as the base line) (WHO, 2013). To achieve these targets, the health department apart, other departments such as the departments of solid waste management, building, water supply and drainage, too need to work in tandem right from the beginning of the year in all dengue-riddled countries around the world. Preventing Ae. aegypti procreation in a particular city or township by the health department of a municipal corporation alone is literally not feasible. And all concerned need to realize this quinine-coated truth and act accordingly for the benefit of the society.

\section{Acknowledgements}

Instructions for undertaking this Aedes survey first came from Shri Atin Ghosh, Hon'ble Member of the Mayor-in-Council (Health and Engineering) of Kolkata Municipal Corporation-for which the authors express their gratefulness to him. The moral support provided by Dr. Snehangshu Chowdhury, Chief Municipal Health Officer of the corporation, too, is thankfully acknowledged. Dr. Basudeb Mukherjee, Municipal Surveillance Officer of KMC, provided the data on dengue. The authors thank him for this help. Last but not the least, field workers of the 4 Rapid Action Teams worked religiously during the entire period of the survey-a help that the authors immensely appreciate and acknowledge.

\section{References}

Biswas, D. (2007). Dengue Resurgence. Kolkata: Science Association of Bengal.

Biswas, D., Dey, S., Dutta, R. N., \& Hati, A. K. (1993). Observations on the Breeding Habitats of Aedes aegypti in Calcutta Following an Episode of Dengue Haemorrhagic Fever. Indian Journal of Medical Research, 97, 44-46.

Biswas, D., Biswas, B., Mandal, B., Banerjee, A., Mukherjee, T. K., \& Nandi, J. (2011). Evaluating School Students’ Perception about Mosquitoes and Mosquito-Borne Diseases in the City of Kolkata, India. Dengue Bulletin, 35, 223-230.

Cheong, W. H. (1967). Preferred Aedes aegypti Larval Habitats in Urban Areas. Bulletin of the World Health Organization, 36, 586-589.

Gilotra, S. K., Rozeboom, L. E., \& Bhattacharya, N. C. (1967). Observations on Possible Competitive Displacement between Populations of Aedes aegypti Linnaeus and Aedes albopictus Skuse in Calcutta. Bulletin of the World Health Organization, 36, 437-446.

Mukherjee, K. K., Chakraborty, S. K., Dey, P. N., Dey, S., \& Chakraborty, M. S. (1987). Outbreak of Febrile Illness Due to Dengue Virus Type 3 in Calcutta during 1983. Transactions of the Royal Society of Tropical Medicine and Hygiene, 81, 1008-1010.

Paiva, C. A. (1912). Materials for a Survey of the Mosquitoes of Calcutta. Records of Indian Museum, 7, 93-98.

Wattal, B. L. (1964). A Note on Aedes Survey of Calcutta Following an Outbreak of Haemorrhagic Fever in July 1963. Indian Journal of Medical Research, 52, 710-718.

WHO (2013). WHO Global Strategy for Dengue Prevention and Control. Public Health, 24, 14-17. 